\title{
Analisis Risiko Kecelakaan Kerja Pada Pemeliharaan Alat Container Crane dan Rubber Tyred Gantries
}

\author{
Jhierren K. T. Arnold, ${ }^{1}$ Diana V. D. Doda, ${ }^{2}$ Rahayu H. Akili. ${ }^{2}$
}

\author{
${ }^{1}$ Program Studi Ilmu Kesehatan Masyarakat Fakultas Kesehatan Masyarakat Universitas \\ Sam Ratulangi Manado \\ ${ }^{2}$ Fakultas Kesehatan Masyarakat Universitas Sam Ratulangi Manado \\ Email: vandadoda@unsrat.ac.id
}

\begin{abstract}
Occupational accidents in Indonesia continue to increase every year, requiring policies and actions that can reduce cases of occupational accidents. Risk management is one of the systems for preventing and reducing risks. In the implementation of risk management, the use of HIRARC is one of the methods to identify hazards, conduct risk assessments, and risk control. In the maintenance process of container crane and rubber-tired gantries, potential hazards may occur. The research aims to identify hazards, conduct a risk assessment, and recommend the risk control on the maintenance activities of the container crane and rubbertired gantries. The study uses qualitative methods with information sources namely: corporate leaders, K3 experts, supervision, and worker technicians. Qualitative data is obtained based on the results of in-depth interview and site observation. The research shows that there are eight job processes with several hazards identified in the maintenance process of container crane and rubber-tired gantries, namely mechanical hazards, electrical hazards, fire hazards, physical hazards, and chemical hazards. The hazards were at the low-risk to high-risk level. It is necessary to apply risk management using the HIRARC method as an evaluation system in risk control.
\end{abstract}

Keywords: risk management, HIRARC, maintenance container crane and rubber-tyred gantries

\begin{abstract}
Abstrak: Kecelakaan kerja di Indonesia terus mengalami peningkatan setiap tahun, sehingga membutuhkan penerapan manajem risiko yang bertujuan untuk mencegah dan mengurangi risiko. Metode HIRARC menjadi salah satu cara untuk dapat mengidentifikasi bahaya, melakukan penilaian risiko dan pengendalian risiko pada tindakan pemeliharaan alat container crane dan rubber tyred gantriesyang proses pekerjaannya menghasilkan potensi bahaya dan risiko. Penelitian bertujuan untuk mengetahui identifikasi bahaya, melakukan penilaian risiko dan mengetahui pengendalian risiko pada tindakan pemeliharaan alat container crane dan rubber tyred gantries. Penelitian ini menggunakan metode kualitatif dengan sumber informasi: Pemimpin perusahaan, ahli K3, supervisi dan pekerja teknisi. Data kualitatif diperoleh berdasarkan hasil wawancara mendalam dengan menggunakan model analisis data Mile dan Huberman. Hasil penelitian menunjukan terdapat delapan proses pekerjaan dengan bahaya yang teridentifikasi pada tindakan pemeliharaan alat container crane dan rubber tyred gantries yaitu bahaya mekanik, bahaya elektrik, bahaya kebakaran, bahaya fisik dan bahaya kimia dengan penilaian risiko berada pada tingkatan risiko rendah sampai risiko tinggi. Diperlukan penerapan manajemen risiko dengan menggunakan metode HIRARC sebagai sistem evaluasi dalam pengendalian risiko.
\end{abstract}

Kata kunci: manajemen risiko, HIRARC, pemeliharaan container crane dan rubber tyred gantries

\section{PENDAHULUAN}

Kecelakaan kerja di Indonesia terus mengalami peningkatan sehingga membu- tuhkan kebijakan dan tindakan untuk dapat mengurangi kasus kecelakaan kerja. Data kecelakaan kerja di Indonesia melalui 
Badan Penyelenggara Jaminan Sosial (BPJS) Ketenagakerjaan mencatat pada Tahun 2016 jumlah kecelakaan kerja sebanyak 101.368 kasus, tahun 2017 sebanyak 123.041 kasus kecelakaan kerja, tahun 2018 sebanyak 173.415 kasus kecelakaan kerja dan di akhir September 2019 total kecelakaan kerja sebanyak 130.923 kasus. $^{1}$

Salah satu sistem yang bertujuan untuk mencegah dan mengurangi faktor risiko adalah Sistem Manajemen Kesehatan dan Keselamatan Kerja (SMK3). Upaya penerapan SMK3 diharapkan dapat mencegah dan mengurangi risiko terjadinya kecelakaan kerja maupun penyakit akibat kerja. ${ }^{2}$

Penerapan SMK3 memiliki tujuan utama dalam mengelola risiko (risk management) yang berkaitan dengan kegiatan perusahaan guna terciptanya tempat kerja yang aman, efisien dan produktif. Manajemen Risiko K3 merupakan analisa risiko dengan tujuan untuk mencegah terjadinya kecelakaan yang dilakukan secara menyeluruh dengan suatu sistem perencanaan yang baik. Pertimbangan dalam melakukan risk management dalam suatu perusahaan harus berdasarkan tinjauan awal dan peraturan perundangundangan yang berlaku serta persyaratan standar. ${ }^{3}$ Dalam pelaksanaan-nya manajemen risiko memerlukan metode yang dapat dipakai untuk mengidentifikasi bahaya diantaranya HAZOP, JSA dan HIRARC. $^{4}$

HIRARC merupakan metode untuk mengidentifikasi bahaya, menilai risiko dan melakukan pengendalian risiko berdasarkan hasil dari penilaian risiko yang diperoleh dengan tujuan untuk membuat program yang dapat mengurangi kejadian kecelakaan kerja. Proses HIRARC yang dilakukan secara menyeluruh akan menghasilkan sebuah dokumen HIRARC yang dapat digunakan dalam pengendalian bahaya kecelakaan kerja. ${ }^{4}$

Bahaya berpotensi menyebabkan cedera atau kesehatan yang buruk, sehingga perlu diidentifikasi sebelum risiko yang terkait dengan bahaya ini dapat terjadi. Identifikasi bahaya merupakan tahapan pertama dalam upaya mengetahui adanya potensi bahaya dalam kegiatan pekerjaan. Pada setiap pekerjaan yang melaksanakan identifikasi bahaya harus dilakukan pertimbangan kondisi sebagai berikut: (1) Kondisi operasi normal $(\mathrm{N})$ : Pekerjaan sehari-hari dan sesuai prosedur, (2) Kondisi operasi abnormal (A): Pekerjaan di luar prosedur, dan (3) Kondisi darurat (E): Keadaan yang sulit dikendalikan. ${ }^{4}$

Risiko merupakan manifestasi potensi bahaya yang mengakibatkan kemungkinan kerugian menjadi lebih besar. Dalam proses pengolahannya, tingkat risiko memiliki perbedaan satu sama lain mulai dari risiko yang paling rendah sampai ke tingkat risiko yang paling tinggi. ${ }^{8}$ Potensi bahaya yang ditemukan pada tahap identifikasi bahaya akan dilakukan penilaian risiko guna menentukan risk rating (tingkat risiko) dari bahaya tersebut. Penilaian risiko berpedoman pada skala Australian Standard/ New Zealand Standard untuk manajemen risiko dengan rumus level risiko merupakan hasil perkalian antara nilai likehood dan consequence. $^{4}$

Hasil dari penilaian risiko akan dijadikan dasar untuk melakukan risk control (pengendalian risiko). Risk control bertujuan untuk mengurangi tingkat risiko dari suatu potensi bahaya yang ada. Bahaya yang masuk dalam kategori low risk (risiko rendah), medium risk (risiko sedang), high risk (risiko tinggi) dan very high risk (risiko sangat tinggi) akan ditindaklanjuti dengan risk control. Pengendalian risiko dilakukan dengan menggunakan Hirarki Pengendalian yang terdiri dari: (1) Eliminasi adalah pengendalian yang bersifat menghilangkan sumber bahaya secara langsung, (2) Substitusi adalah penambahan alat atau mesin untuk membantu pengerjaan yang secara manual, (3) Perancangan adalah teknik rekayasa alat, mesin atau tempat kerja menjadi lebih aman, (4) Administrasi adalah sistem pengendalian yang bertujuan agar tenaga kerja dapat terlindung dari paparan bahaya, dan (5) Alat Pelindung Diri (APD) merupakan pengendalian secara langsung bagi pekerja untuk melindungi diri. 
Container crane merupakan peralatan bongkar muat yang digunakan untuk membongkar atau memuat petikemas/ container dari kapal ke dermaga/pelabuhan. Container crane dinilai lebih cepat dalam melakukan kegiatan bongkar muat dibandingkan dengan alat bongkar muat seperti Harbour Mobile Crane (HMC), Shore Crane (Derek Darat) dan Ship Crane (Derek Kapal). ${ }^{9}$

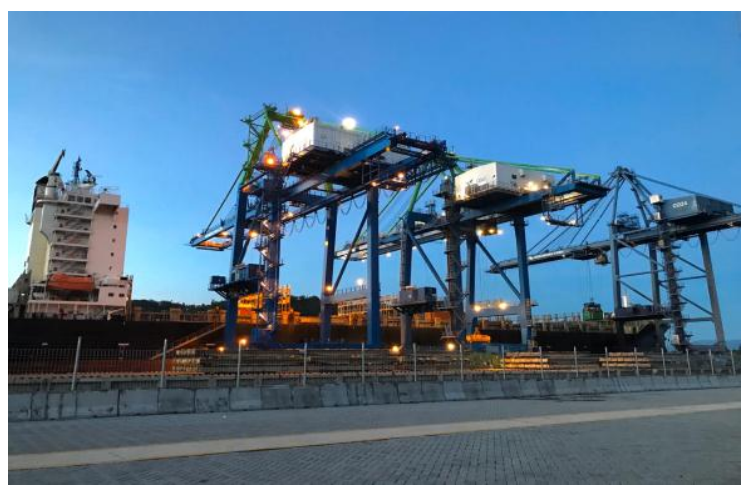

Gambar 1. Alat bongkar muat container crane

Rubber tyred gantries atau yang disebut dengan RTG adalah jenis gantry crane yang digunakan untuk menumpuk dan mengambil container pada lapangan container. RTG crane mempunyai tinggi 12 - 15 meter. Dalam pengoperasiannya, RTG crane dapat melakukan proses bongkar muat dengan beban container berkisar 36 sampai 40 ton dengan kebutuhan listrik rata-rata $300-500 \mathrm{~kW}$ yang dialirkan dari generator listrik, oleh karena itu. ${ }^{6}$

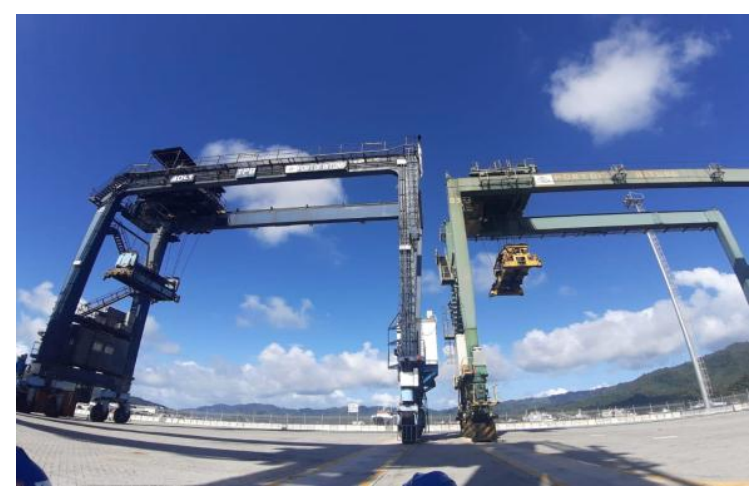

Gambar 2. Alat bongkar muat rubber tyred gantries

\section{METODE PENELITIAN}

Penelitian ini menggunakan metode kualitatif yang dilaksanakan pada bulan April-Juli 2020, berlokasi di area Terminal Petikemas Bongkar Muat Bitung. Pengumpulan data dilakukan dengan cara melakukan wawancara mendalam, observasi dan studi dokumen secara online. Informasi yang diperoleh bersumber dari: Pemimpin perusahaan, ahli K3, supervisi dan pekerja teknisi. Data kualitatif diperoleh berdasarkan hasil wawancara mendalam dengan menggunakan model analisis data Mile dan Huberman. Validasi penelitian berdasarkan triangulasi sumber dan triangulasi metode.

Tabel 1. Karakteristik Informan Penelitian

\begin{tabular}{ccccc}
\hline & Umur & Jabatan & Pendidikan Terakhir & Masa Kerja \\
\hline Informan I & 42 thn & Site Manager & S1-Teknik & 7 thn \\
Informan II & 29 thn & Safety Officer & D3-Elektro & 3 thn \\
Informan III & 37 thn & Supervisior & SMK Jurusan Elektro & 7 thn \\
Informan IV & 28 thn & Teknisi CC & SMK Jurusan Elektro & 5 thn \\
Informan V & 22 thn & Teknisi RTG & SMK Jurusan Teknik Alat Berat & 4 thn \\
\hline
\end{tabular}




\section{HASIL PENELITIAN Kriteria informan}

Pengambilan informan sebagai subjek penelitian didasarkan oleh jabatan atau tanggungjawab dalam pekerjaan, umur, pendidikan terakhir dan masa kerja. Karakteristik Informan Penelitian dapat dilihat pada tabel 5. Informan pada penelitian kualitatif ini mengikut sertakan lima orang yang merupakan informan kunci dalam perusahaan ini.

\section{Hasil wawancara identifikasi bahaya pada alat container crane dan rubber tyred gantries}

Pertanyaan yang diberikan kepada informan disesuaikan dengan tanggung jawab pekerjaan informan.

1. Bagimana menurut bapak, pekerjaan apa saja yang dilakukan pada tindakan pemeliharaan alat $C C$ dan $R T G$ ?

\begin{tabular}{|c|c|}
\hline aforman & Jawaban \\
\hline I & $\begin{array}{l}\text { "...pekerjaan yang wajib itu } \\
\text { melakukan pengecakan alat CC dan } \\
\text { RTG apakah ada kerusakan atau } \\
\text { tidak. Salah satu contohnya itu } \\
\text { melakukan running engine..." }\end{array}$ \\
\hline II & $\begin{array}{l}\text { "...maintenance engine (pemeliha- } \\
\text { raan mesin CC dan RTG), penge- } \\
\text { cekan listrik, pengelasan, potong } \\
\text { besi dan pengecekan alat untuk } \\
\text { melihat apakah ada kerusakan yang } \\
\text { perlu diperbaiki..." }\end{array}$ \\
\hline III & $\begin{array}{l}\text { "...saya sebagai supervisior tugas- } \\
\text { nya yaitu melakukan perencanaan } \\
\text { terhadap perbaikan atau pemeli- } \\
\text { haraan alat..." }\end{array}$ \\
\hline IV & $\begin{array}{l}\text { “....saya sebagai mekanik bertang- } \\
\text { gung jawab untuk melakukan } \\
\text { pemeliharaan terhadap alat } C C .\end{array}$ \\
\hline & $\begin{array}{l}\text { "...Pekerjaan yang dilakukan dianta- } \\
\text { ranya, mengganti wire rope (tali } \\
\text { kawat), lepas wheel trolley, ganti air } \\
\text { radiator, ganti v-belt dan penge- } \\
\text { cekan masalah listrik..." }\end{array}$ \\
\hline V & $\begin{array}{l}\text { “...saya sebagai mekanik untuk } \\
\text { pemeliharaan alat RTG. Pekerjaan } \\
\text { yang dilakukan seperti, ganti wire } \\
\text { rope (tali kawat), mengganti rel } \\
\text { RTG, pemasangan lampu RTG dan } \\
\text { ganti kabelfestoon. }\end{array}$ \\
\hline
\end{tabular}

Simpulan: pekerjaan wajib yang dilakukan yaitu pemeliharaan alat $C C$ dan $R T G$ diantaranya pengecekan listrik, pengelasan, potong besi, ganti wire rope, mengganti air radiator, lepas wheel trolley, ganti rail $R T G$, pemasangan lampu $R T G$, ganti $v$-belt dan running engine.

2. Bagaimana menurut bapak, jenis bahaya apa saja yang terdapat pada proses pekerjaan pemeliharaan alat bongkar muat $C C$ dan $R T G$ ?

\begin{tabular}{|c|c|}
\hline Informan & Jawaban \\
\hline I & $\begin{array}{l}\text { "...yang paling bahaya itu } \\
\text { terjatuh dari ketinggian..." }\end{array}$ \\
\hline II & $\begin{array}{l}\text { "....bahaya yang bisa terjadi } \\
\text { misalnya bahaya mekanikal, } \\
\text { bahaya listrik dan adapun } \\
\text { bahaya di tempat mesin karena } \\
\text { ada tumpahan oli dan minyak } \\
\text { serta bahaya panas akibat } \\
\text { pengelasan karena ada percikan } \\
\text { api. Bagian mesin juga kadang } \\
\text { ada bahaya bising..." }\end{array}$ \\
\hline III & $\begin{array}{l}\text { "....yang paling bahaya } \\
\text { pekerjaan di tempat yang tinggi, } \\
\text { kemudian bahaya listrik dan } \\
\text { bahaya mekanikal yang paling } \\
\text { sering terjadi contohnya potensi } \\
\text { terjepit dan terjatuh..." }\end{array}$ \\
\hline $\begin{array}{c}\text { Pendukung } \\
\text { I }\end{array}$ & $\begin{array}{l}\text { “...bahaya listrik dan bahaya } \\
\text { jika terjatuh alat-alat yang } \\
\text { digunakan saat bekerja...” }\end{array}$ \\
\hline $\begin{array}{l}\text { Pendukung } \\
\text { II }\end{array}$ & $\begin{array}{l}\text { “..bahaya mekanikal misalnya } \\
\text { terjatuh alat wire rope (tali } \\
\text { kawat), terjatuh dari ketinggian } \\
\text { saat melakukan pekerjaan } \\
\text { mengganti rail RTG...” }\end{array}$ \\
\hline
\end{tabular}

Simpulan: terdapat bahaya mekanikal seperti jatuh dari ketinggian terjepit alat dan tertimpah alat. Terdapat juga bahaya listrik, bahaya kebakaran, bahaya fisik dan bahaya kimia yang berasal dari tumpahan minyak. 
Hasil wawancara penilaian risiko pada alat container crane dan rubber tyred gantries

Penilaian risiko dilakukan dengan berpedoman pada skala Australian Standard/ New Zealand Standard untuk manajemen risiko. ${ }^{4}$

1. Menurut bapak, bagaimana kemungkinan terjadinya kecelakaan dengan kondisi peralatan yang bapak gunakan saat bekerja?

\begin{tabular}{c} 
Informan \\
\hline IV “...alatnya masih layak untuk \\
digunakan. Kalau pun ada yang \\
rusak masih bisa diperbaiki, \\
misalnya terkadang untuk safety belt \\
kita harus melakukan pengecekan \\
setiap hari untuk menjaga kondisi \\
alat tetap aman agar ketika \\
digunakan pada tempat pekerjaan \\
yang tinggi safety belt tidak putus \\
karena jika safety belt putus akan \\
berbahaya bagi keselamatan....” \\
Pendu- "masih layak untuk digunakan.. tapi \\
kung ada beberapa alat yang \\
V \\
kemungkinan dapat mengakibatkan \\
tangan terjepit misalnya chain block \\
yang digunakan saat pekerjaan \\
melepas wheel trolley...”
\end{tabular}

Simpulan: kemungkinan kecelakaan kerja yang terjadi tergantung pada kondisi alat misalnya untuk penggunaan safety belt di area kerja yang tinggi dan penggunaan alat chain block saat melakukan pekerjaan melepas wheel trolley.

2. Apakah bapak pernah mengalami kecelakaan kerja saat melakukan proses pekerjaan (atau hampir mengalami kecelakaan) selama bapak bekerja bagaimana tingkat keparahannya?

\begin{tabular}{cl}
\hline Informan & \multicolumn{2}{c}{ Jawaban } \\
\hline II & "...kalau dari saya belum ada. \\
& tapi sebelum saya ada kecelakaan \\
& kalau yang terjadi kemarin \\
& sempat mendapatkan perawatan \\
& karena yang luka di jari tangan \\
& sehingga harus segara diambil \\
& tindakan..."
\end{tabular}

IV "...kalau saya hampir kena, jadi alat gurinda yang saya gunakan jatuh dan hampir mengenai kaki saya..."

Pendukung “...kalau saya belum pernah, tapi $\mathrm{V}$ kemarin ada kecelakaan tapi langsung ditangani.... kalau yang kemarin teman saya bisa-bisa kehilangan jari kalu tidak segera ditarik keluar dari alat.... kemarin sampai harus dibawah ke pusat kesehatan untuk perawatan karena jari tangan luka akibat terjepit alat saat mengganti v-belt..."

Simpulan: ada kasus kecelakaan yang terjadi sehingga mengakibatkan salah satu pekerja harus menjalani perawatan akibat tangan yang terjepit alat saat mengganti $v$ belt.

\section{Hasil Wawancara Pengendalian Risiko pada alat container crane dan rubber tyred gantries}

1. Bagaimana menurut bapak, pengendalian apa saja yang bapak harapkan terhadap risiko-risiko kecelakaan yang belum dilakukan oleh perusahaan?

\begin{tabular}{cc}
\hline Informan & \multicolumn{2}{c}{ Jawaban } \\
\hline IV “..kalau kita dari perusahaan \\
sudah ada APD tapi yang masih \\
kurang itu sarung tangan harus \\
ditambah lagi..” \\
Pendukung “...untuk sementara ini masih \\
V memadai untuk saya.karena \\
disediakan APD dari perusahaan \\
seperti sepatu safety, helm safety, \\
body harness untuk tempat kerja \\
yang tinggi dan seragam \\
safety...”
\end{tabular}

Simpulan: perusahaan sudah menyediakan APD tapi jumlahnya masih kurang.

Hasil proses HIRARC (hazard identification, risk assessment, risk control) pada tindakan pemeliharaan alat bongkar muat container crane dan rubber tyred gantries dapat dilihat pada tabel 2 dan tabel 3. 
Tabel 2. Penilaian risiko dan pengendalian risiko pada alat container crane

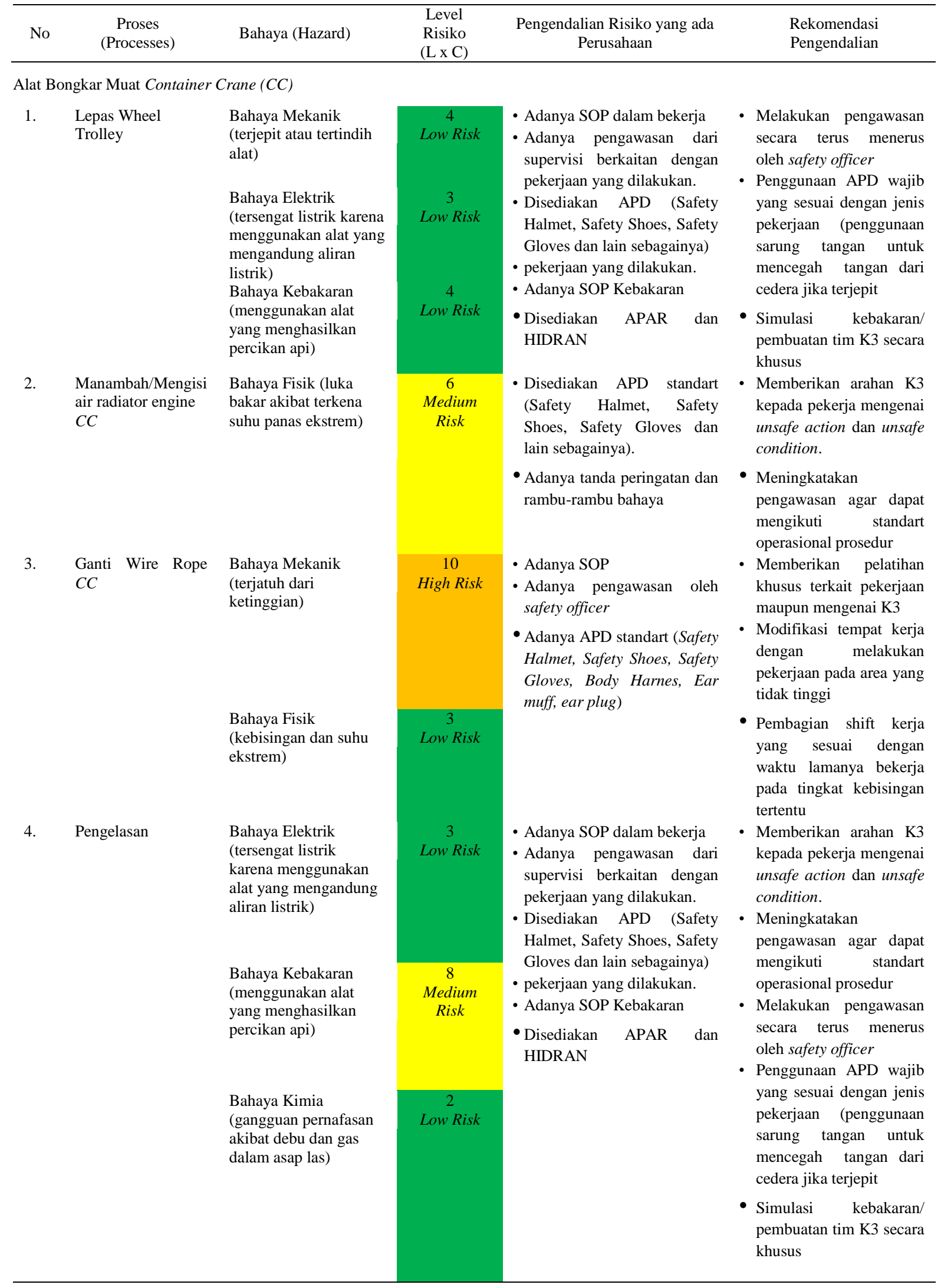


Tabel 3. Penilaian risiko dan pengendalian risiko pada alat rubber tyred gantries

\begin{tabular}{|c|c|c|c|c|c|}
\hline No & Proses & Bahaya & $\begin{array}{l}\text { Skala Risiko } \\
\quad(\mathrm{L} \times \mathrm{C})\end{array}$ & $\begin{array}{l}\text { Pengendalian risiko yang ada } \\
\text { pada perusahaan }\end{array}$ & $\begin{array}{l}\text { Rekomendasi } \\
\text { Pengendalian }\end{array}$ \\
\hline \multicolumn{6}{|c|}{ Alat Bongkar Muat Rubber Tyred Gantries (RTG) } \\
\hline 1. & $\begin{array}{l}\text { Pemasangan } \\
\text { lampu penerangan } \\
R T G\end{array}$ & $\begin{array}{l}\text { Bahaya Mekanik (jatuh } \\
\text { dari ketinggian) }\end{array}$ & $\begin{array}{c}8 \\
\text { Medium Risk }\end{array}$ & $\begin{array}{l}\text { - Melakukan pekerjaan sesuai } \\
\text { SOP/Prosedur } \\
\text { - Pemberian tanda bahaya } \\
\text { - Penggunaan APD (Safety } \\
\text { Helmet, Safety Shoes, } \\
\text { Safety Clothes) } \\
\text { - Pengawasan oleh safety } \\
\text { Officer } \\
\text { - Memberikan pengarahan } \\
\text { tentang K3 }\end{array}$ & $\begin{array}{lr}\text { - Pengawasan oleh } & \text { safety } \\
\text { Officer } & \text { dengan } \\
\text { memberikan } & \text { reward } \\
\text { bagi pekerja } & \text { yang } \\
\text { mentaati } & \text { mengenai } \\
\text { aturan yang } & \text { berkaitan } \\
\text { dengan K3 } & \text { sebagai } \\
\text { motivasi bagi } & \text { pekerja } \\
\text { lain } & \text { untuk } \\
\text { memperhatikan } & \text { budaya } \\
\text { K3 } & \end{array}$ \\
\hline \multirow[t]{2}{*}{2.} & \multirow[t]{2}{*}{ Ganti Rail $R T G$} & $\begin{array}{l}\text { Bahaya Mekanik (jatuh } \\
\text { dari ketinggian) }\end{array}$ & $\stackrel{8}{8}$ & $\begin{array}{l}\text { - Melakukan pekerjaan sesuai } \\
\text { SOP/Prosedur } \\
\text { - Pemberian tanda bahaya }\end{array}$ & \multirow{2}{*}{$\begin{array}{l}\text { - Pengawasan oleh safety } \\
\text { Officer } \\
\text { - Memberikan pengarahan } \\
\text { tentang K3 }\end{array}$} \\
\hline & & $\begin{array}{l}\text { Bahaya kimia (gangguan } \\
\text { kulit, gangguan } \\
\text { pernafasan eceran bahan } \\
\text { kimia seperti oli, bahan } \\
\text { bakar) }\end{array}$ & $\begin{array}{c}4 \\
\text { Low Risk }\end{array}$ & $\begin{array}{lrr}\bullet \text { Penggunaan } & \text { APD } & \text { (Safety } \\
\text { Helmet, Safety } & \text { Shoes, } \\
\text { Safety Clothes, } & \text { Body } \\
\text { Harnnes, Safety Gloves) }\end{array}$ & \\
\hline 3. & Ganti v-belt & $\begin{array}{l}\text { Bahaya Mekanik } \\
\text { (terjepit alat saat } \\
\text { pergantian v-belt) }\end{array}$ & $\begin{array}{c}9 \\
\text { Medium Risk }\end{array}$ & $\begin{array}{l}\text { - Melakukan pekerjaan sesuai } \\
\text { SOP/Prosedur } \\
\text { - Pemberian tanda bahaya } \\
\text { - Penggunaan APD (Safety } \\
\text { Helmet, Safety Shoes, } \\
\text { Safety Clothes, Body } \\
\text { Harnnes, Safety Gloves) }\end{array}$ & $\begin{array}{l}\text { - Pengawasan oleh safety } \\
\text { Officer } \\
\text { - Memberikan pengarahan } \\
\text { tentang K3 }\end{array}$ \\
\hline 4. & $\begin{array}{l}\text { Running engine } \\
R T G\end{array}$ & $\begin{array}{l}\text { Bahaya Mekanik } \\
\text { (terjatuh dari alat } R T G \text { ) }\end{array}$ & $\begin{array}{c}12 \\
\text { High Risk }\end{array}$ & $\begin{array}{l}\text { - Melakukan pekerjaan sesuai } \\
\text { SOP } \\
\text { - Pengawasan oleh safety } \\
\text { Officer } \\
\text { - Penggunaan APD (Safety } \\
\text { Helmet, Safety Shoes, Body } \\
\text { Harnes, Jas Hujan) }\end{array}$ & $\begin{array}{l}\text { - Memberikan Pelatihan } \\
\text { Khusus } \\
\text { - Modifikasi tempat kerja } \\
\text { misalnya melakukan } \\
\text { pekerjaan pada area } \\
\text { yang tidak tinggi } \\
\text { (workshop) } \\
\text { - Pembagian durasi kerja } \\
\text { tidak lebih dari } 8 \text { jam } \\
\text { kerja. }\end{array}$ \\
\hline
\end{tabular}

\section{BAHASAN \\ Identifikasi Bahaya}

Pada setiap proses pekerjaan telah teridentifkasi potensi bahaya yaitu: bahaya mekanik (jatuh dari ketinggian, tertimpah dan kejatuhan alat), bahaya elektrik, bahaya kebakaran, bahaya kimia (ceceran bahan bakar, oli, asap las) dan bahaya fisik (kebisingan, suhu panas ekstrem). Potensi bahaya yang pertama yaitu bahaya mekanik seperti jatuh dari ketinggian, tertimpah dan kejatuhan alat yang dapat terjadi akibat kondisi peralatan yang digunakan tidak aman dan tindakan pekerja yang tidak menggunakan alat pelindung diri (APD). Hal ini sejalan dengan penelitian yang dilakukan Alfitri (2019) mengenai identi- fikasi bahaya pada kegiatan bongkar muat petikemas, bahwasanya potensi bahaya terjatuh dapat terjadi apabila tenaga kerja tidak memperhatikan pijakannya atau dikarenakan tindakan yang tidak aman dari pekerja. $^{8}$

Potensi bahaya kedua yang teridentifikasi yaitu bahaya listrik dan bahaya kebakaran. Penggunaan alat yang memerlukan aliran listrik dan yang mengahasilkan percikan api seperti proses pengelasan merupakan salah satu sumber bahaya yang dapat mengakibatkan pekerja kesetrum dan berpotensi kebakaran apabila percikan api berkontaminasi dengan bahan bakar minyak. Bahaya selanjutnya yang dapat terjadi yaitu bahaya kimia yang berasal dari 
asap las dapat mengakibatkan gangguan pernafasan dan gangguan mata. Pada penelitian yang dilakukan di PT. X, hasil potensi bahaya pada tindakan perawatan dan perbaikan ada pada proses pengelasan, yang mana potensi bahaya yang diakibatkan yaitu iritasi karena percikan api yang mengenai kulit dan mata serta gangguan pernafasan akibat menghirup gas/uap las? .

Potensi bahaya yang terakhir yaitu bahaya fisik seperti bahaya suhu panas saat melakukan pekerjaan menambah/mengisi air radiator $C C$ yang mana pekerja tidak menunggu mesin dingin terlebih dahulu sebelum manambah/mengisi air radiator. Marbun (2015) menyebutkan bahwa suhu panas yang bersumber dari radiator menyebabkan bagian pundak depan dan dada pekerja mengalami luka bakar ringan dikarenakan kelalaian pekerja yang tidak mengikuti operasional prosedur saat mengisi air radiator. ${ }^{10}$

\section{Penilaian Risiko}

Penilaian risiko merupakan tahapan yang dilakukan setelah mengidentifikasi bahaya yang bertujuan untuk mengetahui bahaya mana yang dapat dijadikan prioritas dalam pengendalian risiko. Risiko yang tidak dapat diterima, harus dilakukan pengendalian risiko sesuai dengan tingkat risikonya agar tidak mengakibatkan kerugian bagi pekerja maupun perusahaan. ${ }^{11}$ Penilaian risiko pada masing-masing jenis pekerjaan dapat dilihat pada Table 1 dan 2, dimana level risiko berada pada level ringan sampai dengan berat.

Pekerjaan pergantian v-belt yang merupakan pergantian kabel karet yang berfungsi sebagai penghubung/pengantar daya putaran mesin seperti kipas radiator, water pump, altenator. Bahaya mekanik merupakan bahaya yang kemungkinan dapat terjadi saat proses pergantian v-belt, seperti tergores, luka memar akibat terjepit alat dengan tingkat kategori risiko ringan. ${ }^{11}$ Alfitri (2019) menyebutkan bahwa, kejadian memar dan luka gores dapat terjadi apabila tenaga kerja bongkar muat tidak menggunakan APD berupa sarung tangan. ${ }^{8}$

Penilaian risiko pada pekerjaan-pekerjaan mengganti wire rope (tali sling) crane. Sanjayani dan Martiana (2018) menyebutkan bahwa, wire rope (tali sling) dapat sewaktu-waktu putus saat proses bongkar muat, sehingga diperlukan pengecekan dan pemeliharaan secara berkala. ${ }^{11}$ Pekerjaan dengan bahaya mekanik yaitu terjatuh dari ketinggian. Berdasarkan hasil penilaian risiko pekerjaan ini digolongkan pada tingkatan "High Risk" dengan skala risiko sepuluh $^{11}$. Hal ini dikarenakan tingkatan kemungkinan terjadinya insiden pada pekerjaan ini ada pada angka 2 yaitu sangat jarang terjadi. Kemudian tingkat keparahan ada pada angka 5 atau apabila insiden jatuh dari ketinggian ini terjadi dapat menyebabkan luka permanen bahkan kematian bagi pekerja. Berdasarkan hasil penilaian risiko pekerjaan ini digolongkan pada tingkatan "High Risk" dengan skala risiko 12, karena tingkat kemungkinan terjadinya bahaya ini ada pada angka 3 atau kemungkinan insiden dapat terjadi atau dalam kurun waktu 1-2 tahun ada insiden yang terjadi dan untuk tingkat keparahan berada pada angka 4 karena insiden yang terjadi akan mengakibatkan cidera berat atau atau cedera permanen akibat jatuh dari ketinggian yang merugikan pekerja. ${ }^{12}$

\section{Pengendalian Risiko}

Pengendalian risiko dilakukan untuk mengurangi tingkat risiko yang dapat mengakibatkan kerugian bagi perusahaan maupun pekerja. Pengendalian risiko merupakan tahap akhir yang sangat penting untuk dapat menentukan keseluruhan manajemen risiko. ${ }^{11}$

Hasil studi dokumentasi dan pengamatan yang dilakukan, Terminal Petikemas Bongkar Muat site Bitung telah melakukan dua tingkatan hirarki pengendalian risiko diantaranya pengendalian administratif dan alat pelindung diri (APD). Pengendalian administratif yang dilakukan yaitu pemasangan tanda-tanda peringatan bahaya, pengarahan $\mathrm{K} 3$, pengaturan shift kerja, serta sertifikat ahli K3 bagi salah satu 
pekerja yang menjadi safety officer. Pengendalian alat pelindung diri (APD) yang disedikan yaitu penggunaan helm keselamatan (safety helmet), sepatu keselamatan (safety shoes), sarung tangan (safety gloves) dan baju keselamatan (safety clothes). Peneliti merekomendasikan untuk tetap meneruskan pengendalian risiko yang sudah ada dan menambah beberapa pengendalian seperti melakukan pelatihan khusus bagi pekerja dalam melakukan pekerjaan pemeliharaan container crane dan rubber tyred gantries, melakukan penerapan manajemen risiko salah satunya membuat dokumen HIRARC dan pengawasan dari safety officer secara terusmenerus terhadap penggunaan alat pelindung diri (APD) saat bekerja. Senjayani dan Martiana (2018) menyebutkan bahwa melakukan pelatihan dan pengarahan merupakan tanggungan dari petugas safety untuk memberikan pengatahuan tentang pentingnya penggunaan alat pelindung diri (APD) saat bekerja yang dapat mencegah terjadinya kecelakaan. ${ }^{11}$

\section{SIMPULAN}

Potensi bahaya yang teridentifikasi pada tindakan pemeliharaan alat bongkar muat Container Crane dan Rubber Tyred Gantries meliputi delapan jenis pekerjaan dengan jenis bahaya keselamatan dan bahaya kesehatan diantaranya: bahaya mekanik, bahaya elektrik, bahaya kebakaran, bahaya fisik, dan bahaya kimia dengan tingkatan "low risk" atau risiko rendah, tingkatan medium risk atau risiko sedang dan tingkatan "high risk" atau risiko tinggi. Pengendalian risiko yang disarankan yaitu melakukan pengawasan dan pengarahan tentang K3, memberikan pelatihan khusus terkait jenis pekerjaan dan penerapan analisis bahaya dan risiko untuk manajemen risiko.

\section{Konflik Kepentingan}

Penulis menyatakan tidak terdapat konflik kepentingan dalam studi ini.

\section{DAFTAR PUSTAKA}

1. BPJS Ketenagakerjaan. Angka kecelakaan kerja cenderung meningkat. 2019 Available from: https://www.bpjske tenagakerjaan.go.id/berita/23322/Ang ka-Kecelakaan-Kerja-Cender

2. Yenita RN. Higiene Industri. Yogyakarta: Deepublish, 2017

3. Ramli S. Smart Safety: Panduan Penerapan SMK3 yang Efektif. Jakarta: PT. Dian Rakyat, 2013.

4. Ramli S. Pedoman praktis manajemen risiko dalam perspektif K3 OHS risk management. Jakarta: Dian Rakyat, 2010.

5. Karundeng I, Doda DV, Tucunan AAT. Analisis bahaya dan risiko dengan metode hirarc di departement production PT. Samudera Mulia Abadi Mining Contractor Likupang Minahasa Utara. Jurnal KESMAS, 2018; 7(4). Available from: https://ejournal. unsrat.ac.id/index.php/kesmas/article/ view/23139/22834

6. Prastyorini J, Saputra D. Container crane, container yard dan dermaga terhadap kecepatan bongkar muat petikemas pada terminal nilam multipurpose. Jurnal Baruna Horizon 2018; 1(2):110. Available from: https://jurnal.stia mak.ac.id/index.php/jbh/issue/view/2

7. Pribadi KY, Ekawati, Widjasena B. Analisis pengoprasian pada operator Rubber Tyred Gantry (RTG) di Terminal Petikemas Semarang. Jurnal Kesehatan Masyarakat 2016;4(3):436-46 Available from: http://ejournal-sl. undip.ac.id/index .php/jkm

8. Alfitri J. Analisis potensi bahaya dan risiko kegiatan bongkar muat peti kemas pada pekerja di Pelabuhan PT. Pelindo I (Persero) Cabang Dumai Tahun 2019. [Skripsi]. Medan: Fakultas Kesehatan Masyarakat Universitas Sumatera Utara, 2019. Available from: http://repositori.usu.ac.id/han dle/123456789/24808

9. Supriadi S. Nalhadi, A. Rizaal, A. Identifikasi bahaya dan penilaian risiko $\mathrm{K} 3$ pada tindakan perawatan dan perbaikan menggunakan metode HIRARC (Hazard Identification, Risk Assessment, Risk Control) di PT. X. Seminar Nasional Riset Terapan 2015. Serang, 12 Desember 2015. 
172 eBiomedik, Volume 8, Nomor 2, Juli-Desember 2020, hlm. 163-172

SENASSET 2015: hal.281-6. Available from: https://ejurnal. lppmunsera. org/index.php/senasset/issue/view/1

10. Marbun RJ, Puspitasari NB, Budiawan W. Identifikasi dan analisis risiko keselamatan dan kesehatan kerja pada area produksi PT. Pelita Cengkareng Paper. Industrial Engineering Online Journal. 2015; 4(4). Available from: https://ejournal3.undip.ac.id/index.ph p/ieoj/article/view/9855/9574

11. Senjayani, Martiana T. Penilaian dan pengendalian risiko pada pekerjaan bongkar muat petikemas oleh tenaga kerja bongkar muat dengan crane. JPH RECODE. 2018;1(2): 33-42.
Available from: https://e-journal. unair.ac.id/JPHRECODE/article/view File/16244/8715

12. Saragih WL, Mahyuni EL, Lubis AM. Penilaian risiko kecelakaan kerja pada tenaga kerja bongkar muat di Pelabuhan Teluk Nibung Tanjung Balai Asahan Tahun 2015. Lingkungan dan Keselamatan Kerja. 2015;4(2). Available from: https://www.neliti.com/ id/publications/14589/penilaian-ris iko-kecelakaan-kerja-pada-tenagakerja-bongkar-muat-di-pelabuhante\#cite 